\title{
PERFIL DOS PROGRAMAS INSCRITOS EM 1997
}

\author{
Marta Ferreira Santos Farah \\ Vice-Diretora do Programa GESTÃO PÚBLICA E CIDADANIA \\ Fundação Getulio Vargas
}

\author{
Ricardo Ernesto Vasquez Beltrão \\ Monitor Acadêmico \\ Programa GESTÃO PÚBLICA E CIDADANIA
}

Concluído o período de inscrições do Ciclo de Premiação de 1997 do Programa GESTÃO PÚBLICA E CIDADANIA, atendiam os requisitos exigidos para participação no processo - responsabilidade executiva a cargo de órgão governamental subnacional e pelo menos um ano de efetivo de funcionamento - nada menos que 297 projetos, programas e atividades desenvolvidos em diversas localidades do território nacional.

É verdade que, comparativamente ao primeiro Ciclo de Premiação, realizado no ano anterior, quando foram validadas 629 inscrições, constatou-se uma queda bastante significativa no total de participações. Alguns fatores podem ser levados em consideração para se entender esta queda no número de inscrições.

Em primeiro lugar, fatores diretamente relacionados ao calendário eleitoral. Em 1997 não foram realizadas eleições municipais, ao contrário do que ocorrera em 1996, quando houve maior interesse em obter reconhecimento e conferir visibilidade às iniciativas que vinham sendo desenvolvidas em nível local.

Além disso, mas certamente não de forma menos importante, este mesmo calendário reduziu significativamente a possibilidade de participação do poder municipal em função da exigência de pelo menos um ano de efetivo funcionamento do projeto, programa ou atividade para validação da inscrição no Programa GESTÃO PÚBLICA E CIDADANIA. Empossadas no início do ano, as atuais gestões não puderam inscrever ações recém iniciadas. Ao mesmo tempo, segundo a cultura político-administrativa prevalecente no país, tende a não haver interesse na promoção de iniciativas de gestões anteriores, sobretudo nos casos em que estas são de diferentes correntes político-partidárias. Assim é que a participação de iniciativas municipais sofreu queda de 65,0\% entre 1996 e 1997, com o número de inscrições caindo de 488 para 171, aí incluídas as iniciativas intermunicipais. Esta queda representou nada menos que $95,5 \%$ da diminuição total no número de inscrições, enquanto que no caso de iniciativas de responsabilidade de órgãos estaduais 
o total de inscrições foi quase o mesmo nos dois anos: 125 inscrições em 1997 e 134 em 1996.

Se se considerar o número de municípios que inscreveram programas, por outro lado, observa-se que a queda foi menos expressiva: de 138 em 1996, para 73 municípios em 1997, significando uma redução de $47,1 \%$. Isto permite relativizar o peso dos fatores político-eleitorais apontados anteriormente. Assim, parece ter ocorrido, em 1996, uma grande ênfase ao marketing da administração por parte de alguns governos municipais, o que, de fato, tende a ocorrer em anos eleitorais.

No entanto, o que surpreende no sentido positivo é que, em que pese esta tendência à constituição de uma espécie de "bolha" em períodos pré-eleitorais, a presença de municípios continua expressiva. Para isto, foi necessário que as atuais administrações enfatizassem a continuidade dos programas, inclusive em casos em que houve mudanças de partido ou de corrente política no governo.

Houve maiores dificuldades em atrair novas iniciativas das organizações próprias dos povos indígenas, que em 1997 participaram com apenas uma inscrição contra sete enviadas no ano anterior. Trata-se neste caso de um universo menor - quando comparado aos 4.974 municípios e aos 26 estados e ao Distrito Federal com suas complexas máquinas administrativas - o que certamente tende a tornar a presença de programas indígenas numericamente menos expressiva, passado o primeiro ano do programa de premiação, mobilizador de experiências acumuladas.

Uma análise mais pormenorizada das iniciativas mostra, por sua vez, que, em que pese a queda no montante de inscrições, persistem algumas tendências importantes, identificadas em 1996: a vitalidade dos governos subnacionais em seus diversos níveis, a variedade tanto do conteúdo das iniciativas como das áreas de ação, e ainda a representatividade do território nacional.

Algumas reflexões podem ser feitas a partir de uma análise preliminar dos dois ciclos de premiação.

Um primeiro aspecto a destacar é que, proporcionalmente, a queda no número de localidades que enviaram projetos, programas ou atividades foi bem menos acentuada do que a diminuição no total de inscrições. Como já assinalado anteriormente, na discussão 
sobre a participação municipal, enquanto, em 1996, foram inscritas iniciativas desenvolvidas em 172 diferentes localidades entre estados e municípios, em 1997, este número chegou a 106, resultando numa queda de $38,4 \%$ no número de locais representados. Assim é que ocorreu um processo de desconcentrarão da procedência das inscrições: se, em 1996, a média de inscrições por localidade representada no Ciclo de Premiação foi de 3,7, em 1997, este número foi 2,8.

Estes números podem ser indicativos de que a busca por inovações nas formas de gestão da coisa pública esteja se propagando por novos espaços regionais e locais. Tanto é assim que entre os 172 estados, municípios e organizações próprias dos povos indígenas que inscreveram iniciativas em 1996, apenas 46 (26,7\%) voltaram a fazê-lo em 1997. Entre os 106 que enviaram material para inscrição neste segundo ano, nada menos que 60 $(56,6 \%)$ não o haviam feito no ano anterior. Note-se que entre os 61 estados ou municípios representados entre os 100 semifinalistas de 1996, apenas $19(31,1 \%)$ estavam novamente entre os também 61 estados ou municípios representados no conjunto dos 100 semifinalistas em 1997. Sem que tenha ocorrido nenhuma mudança significativa na estratégia de divulgação do GESTÃo PÚBLICA E CIDADANIA entre os dois períodos, o que parece justificar esta elevada taxa de renovação das localidades representadas é mesmo a disseminação da idéia da necessidade de procura de alternativas viáveis no enfrentamento dos desafios colocados aos governos subnacionais.

Esta tendência parece evidenciar-se também na própria procedência das inscrições. Enquanto em 1996 as cidades ou Estados com maior número de iniciativas desenvolvidas em seus territórios foram, nesta ordem, Belo Horizonte/MG (51 inscrições entre órgãos estaduais e municipais), Franca/SP (35), Estado de São Paulo (35), Campinas/SP (19), Curitiba/PR (19), Ipatinga/MG (19), Estado de Minas Gerais (17), Itabira/MG (15), Vitória/ES (15), Angra dos Reis/RJ (14) e Diadema/SP (13), no Ciclo de Premiação de 1997, os locais com maior número de inscrições foram: Distrito Federal (41), Teresina/PI (15), Estado de São Paulo (14), Vitória/ES (14), Rio de Janeiro/RJ (11), Estado do Rio Grande do Sul (11), Belo Horizonte/MG (9), Recife/PE (7) e Estado do Ceará (7). 
Sob o ponto de vista da distribuição regional, os dados apresentados na tabela abaixo evidenciam, da mesma forma, uma desconcentração em termos da procedência das inscrições e mesmo da representatividade entre os 100 semifinalistas.

TABELA I - DISTRIBUIC̣ÃO REGIONAL DOS INSCRITOS E DOS SEMIFINALISTAS NOS CICLOS DE PREMIAC̣ÃO 1996 E 1997

\begin{tabular}{|c|c|c|c|c|c|c|c|c|}
\hline \multirow{3}{*}{ REGIÕES } & \multicolumn{4}{|c|}{ INSCRITOS } & \multicolumn{4}{|c|}{ SEMIFINALISTAS } \\
\hline & \multicolumn{2}{|c|}{1996} & \multicolumn{2}{|c|}{1997} & \multicolumn{2}{|c|}{1996} & \multicolumn{2}{|c|}{1997} \\
\hline & n.a. & $(\%)$ & n.a. & $(\%)$ & n.a. & $(\%)$ & n.a. & $(\%)$ \\
\hline BRASIL & 629 & $(100,0)$ & 297 & $(100,0)$ & 100 & $(100,0)$ & 100 & $(100,0)$ \\
\hline NORTE & 17 & $(2,7)$ & 9 & $(3,0)$ & 6 & $(6,0)$ & 7 & $(7,0)$ \\
\hline NORDESTE & 62 & $(9,9)$ & 59 & $(19,9)$ & 14 & $(14,0)$ & 17 & $(17,0)$ \\
\hline SUDESTE & 382 & $(60,7)$ & 120 & $(40,4)$ & 53 & $(53,0)$ & 39 & $(39,0)$ \\
\hline SUL & 134 & $(21,3)$ & 63 & $(21,2)$ & 19 & $(19,0)$ & 23 & $(23,0)$ \\
\hline CENTRO-OESTE & 32 & $(5,1)$ & 46 & $(15,5)$ & 8 & $(8,0)$ & 14 & $(14,0)$ \\
\hline + DE 1 REGIÃO & 02 & $(0,3)$ & -- & -- & -- & -- & -- & -- \\
\hline
\end{tabular}

Enquanto, em 1996, os estados e municípios das regiões Norte, Nordeste e CentroOeste foram responsáveis por $17,7 \%$ das inscrições e representaram $32,0 \%$ dos semifinalistas, em 1997, estas mesmas regiões enviaram $38,4 \%$ das inscrições, com as iniciativas correspondendo a $38,0 \%$ dos semifinalistas. Basicamente, o crescimento da participação destas regiões ocorreu de forma concomitante ao decréscimo da presença da região Sudeste.

Em 1997, São Paulo foi a unidade da federação que mais enviou inscrições (59 ou $19,9 \%$ ), seguida do Distrito Federal (41 ou 13,8\%), Rio Grande do Sul (27 ou 9,1\%), Paraná (25 ou 8,4\%) e Minas Gerais (22 ou 7,4\%). Em 1996, ainda que em proporções diversas, quase todos estes estados estiveram também entre os que mais enviaram inscrições: São Paulo (29,3\%), Minas Gerais (22,6\%), Paraná (8,7\%), Rio Grande do Sul $(8,6 \%)$ e Rio de Janeiro $(6,4 \%)$. Note-se que, consideradas apenas as cinco unidades da federação que mais enviaram inscrições nos dois Ciclos de Premiação, estas concentraram $75,6 \%$ das iniciativas em 1996 e apenas 58,6\% em 1997, sendo este mais um indicador da já comentada desconcentração das inscrições pelas diferentes localidades do país. 
PERFIL DOS PROGRAMAS INSCRITOS EM 1997

Outro dado importante diz respeito ao contingente populacional dos municípios e estados nos quais são executados os projetos, programas e atividades participantes do Ciclo de Premiação 1997. Vejamos a tabela II.

TABELA II - DISTRIBUIC̣ÃO DAS INICIATIVAS POR NIVEL DE GOVERNO SEGUNDO PORTE DAS LOCALIDADES ONDE SÃO DESENVOLVIDAS - CICLO DE PREMIIAC̣ÃO 1997

\begin{tabular}{|c|c|c|c|c|c|c|c|c|c|c|c|c|}
\hline \multirow{3}{*}{$\begin{array}{l}\text { número de } \\
\text { habitantes } \\
\text { (em milhares) }\end{array}$} & \multicolumn{6}{|c|}{ INICIATIVAS INSCRITAS } & \multicolumn{6}{|c|}{ LOCALIDADES REPRESENTADAS } \\
\hline & \multicolumn{2}{|c|}{ total } & \multicolumn{2}{|c|}{ estaduais (") } & \multicolumn{2}{|c|}{ municipais $^{(2)}$} & \multicolumn{2}{|c|}{ total } & \multicolumn{2}{|c|}{ estaduais } & \multicolumn{2}{|c|}{ municipais $^{(2)}$} \\
\hline & n.a. & (\%) & n.a. & $(\%)$ & n.a. & $(\%)$ & n.a. & $(\%)$ & n.a. & $(\%)$ & n.a. & $(\%)$ \\
\hline TOTAL & 297 & $(100,0)$ & 122 & $(41,1)$ & 175 & $(58,9)$ & 106 & $(100,0)$ & 38 & $(35,8)$ & 68 & $(64,2)$ \\
\hline até & 13 & $(4,4)$ & 2 & $(0,7)$ & 11 & $(3,7)$ & 12 & $(11,3)$ & 2 & $(1,9)$ & 10 & 110,4 \\
\hline+ de 20 até 50 & 22 & $(7,4)$ & 2 & $(0,7)$ & 20 & $(6,7)$ & 14 & $(13,2)$ & 2 & $(1,9)$ & 12 & $(11,3)$ \\
\hline+ de & 26 & $(8,8)$ & 2 & $(0,7)$ & 24 & $(8,1)$ & 18 & $(17,0)$ & 2 & $(1,9)$ & 16 & $(15,1)$ \\
\hline+ de 1 & 17 & $(5.7)$ & 1 & $(0,3)$ & 16 & $(5,4)$ & 12 & $(11,3)$ & 1 & $(0,9)$ & 11 & $(10,4)$ \\
\hline+ de 2 & 52 & $(17,5)$ & 10 & $(3,4)$ & 42 & $(14,1)$ & 21 & $(19,8)$ & 6 & $(5,7)$ & 12 & $(11,3)$ \\
\hline+ de 5 & 24 & $(8,1)$ & 3 & $(1,0)$ & 21 & $(7,1)$ & 7 & $(6,6)$ & 3 & $(2,8)$ & 4 & $(3,8)$ \\
\hline+ de 1 & 81 & $(27,3)$ & 57 & $(19,2)$ & 24 & $(8,1)$ & 14 & $(13,2)$ & 12 & $(11,3)$ & 2 & $(1,9)$ \\
\hline+ de 5.000 até 10.000 & 50 & $(16,8)$ & 33 & $(11,1)$ & 17 & $(5,7)$ & 7 & $(6,6)$ & 6 & $(5,7)$ & 1 & $(0,9)$ \\
\hline+ de 10.000 & 12 & $(4,0)$ & 12 & $(4,0)$ & -- & -- & 4 & $(3,8)$ & 4 & $(3,8)$ & -- & \\
\hline
\end{tabular}

11) Inclui iniciativas interestaduais e do Distrito Federal. No caso de iniciativas estaduais de alcance municipal ou regional foi considerado o contingente populacional da localidade onde é realizado o projeto, programa ou atividade. (2) Inclui iniciativas intermunicipais e uma organização indigena.

Os dados apresentados revelam que, embora em termos de número total de inscrições o predomínio seja das localidades com contingentes populacionais mais elevados, quando contabilizamos apenas uma vez as que enviaram mais de uma inscrição, a distribuição é bastante equilibrada entre localidades de pequeno, médio e grande porte. Esta diferença pode ser explicada pelo fato de que os municípios e estados maiores tendem a desenvolver maior quantidade de projetos, programas ou atividades uma vez que neles a demanda por serviços é também maior e que a estrutura administrativa tende a ser mais complexa e diversificada.

Mas o que, de fato, interessa ressaltar aqui é que a capacidade inovadora dos governos subnacionais não é característica exclusiva de máquinas administrativas mais complexas e com maior aporte de recursos. Pelo contrário. As pequenas e médias cidades, com até 200 mil habitantes, representam mais da metade das localidades que participaram do Ciclo de Premiação 1997. 
Outra dimensão relevante na análise do Ciclo de 1997 diz respeito ao ano de início dos projetos, programas e atividades. A grande maioria $(91,9 \%)$ foi iniciada nos anos 90 . Nada menos que $65,7 \%$ a partir de 1994. Por outro lado, não é desprezível a quantidade de iniciativas que já contam com quatro ou mais anos de duração $(34,3 \%)$, sinalizando que pode estar ocorrendo uma salutar mudança no tradicional padrão de descontinuidade das políticas públicas a cada mudança de mandato. No caso das iniciativas de âmbito estadual enviadas, $32,0 \%$ são anteriores aos atuais mandatos, iniciados em 1995. Em nível municipal, $25 \%$ são anteriores às gestões do período 1993-1996, o que significa dizer que atualmente já estão passando pelo terceiro mandato em seus municípios desde a sua efetiva implantação. O gráfico a seguir mostra a distribuição das iniciativas por ano de início segundo o nível de governo.

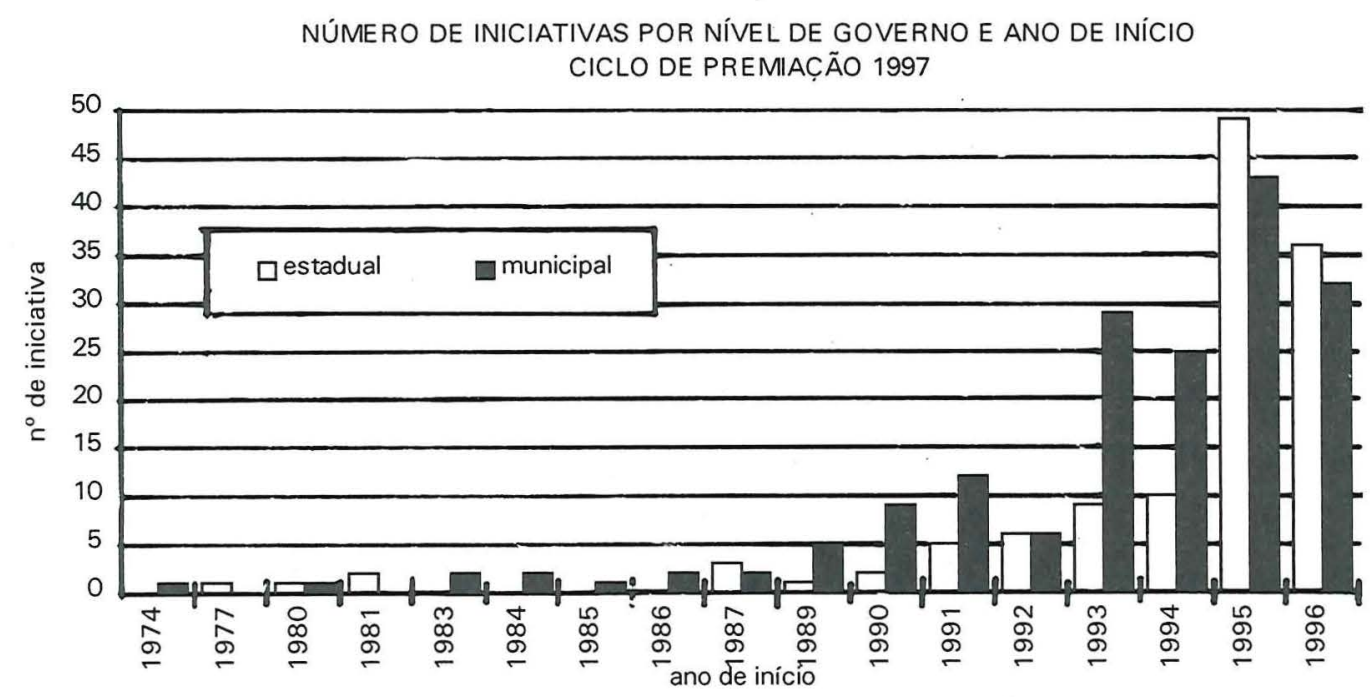

Finalmente, cabe um breve comentário acerca das áreas de ação dos projetos, programas e atividades inscritos no Ciclo de Premiação 1997. De uma forma geral, a comparação com o Ciclo de 1996 revela que praticamente não houve alteração significativa com relação a este aspecto entre os dois anos. A tabela III apresenta alguns dados a respeito. 
TABELA III - ÁREAS DE AC̣ÃO GOVERNAMENTAL DOS INSCRITOS E DOS SEMIFINALISTAS NOS CICLOS DE PREMIAC̣ÃO 1996 E 1997

\begin{tabular}{|c|c|c|c|c|c|c|c|c|c|c|}
\hline \multirow{3}{*}{ áreas de ação governamental (1) } & \multicolumn{5}{|c|}{1997} & \multicolumn{5}{|c|}{1996} \\
\hline & \multicolumn{2}{|c|}{$\begin{array}{c}\text { inscritos } \\
{[\mathrm{A}]}\end{array}$} & \multicolumn{2}{|c|}{$\begin{array}{l}\text { semifinalistas } \\
{[\mathrm{B}]}\end{array}$} & \multirow[t]{2}{*}{$\begin{array}{c}\%[B] / \\
\%[\end{array}$} & \multicolumn{2}{|c|}{$\begin{array}{c}\text { inscritos } \\
\text { [A] }\end{array}$} & \multicolumn{2}{|c|}{$\begin{array}{l}\text { semifinalistas } \\
{[\mathrm{B}]}\end{array}$} & \multirow[t]{2}{*}{$\begin{array}{l}\%[\mathrm{~B}] / \\
\%[\mathrm{~A}]\end{array}$} \\
\hline & n.a. & $(\%)$ & n.a. & $(\%)$ & & \begin{tabular}{l|l} 
n.a. & \\
\end{tabular} & $(\%)$ & \begin{tabular}{l|l} 
n.a. & \\
\end{tabular} & $(\%)$ & \\
\hline total & \multicolumn{2}{|c|}{$297(100,0)$} & \multicolumn{2}{|c|}{$100(100,0)$} & 1,0 & \multicolumn{2}{|c|}{$629(100,0)$} & \multicolumn{2}{|c|}{$100(100,0)$} & 1,0 \\
\hline educação & 60 & $(20,2)$ & 8 & $(8,0)$ & 0,4 & 98 & $(15,6)$ & 9 & $(9,0)$ & 0,6 \\
\hline saúde & 45 & $(15,2)$ & 17 & $(17,0)$ & 1,1 & 81 & $(12,9)$ & 9 & $(9,0)$ & 0.7 \\
\hline criança e adolescente & 27 & $(9,1)$ & 6 & $(6,0)$ & 0.7 & 50 & $(7,9)$ & 9 & $(9,0)$ & 1,1 \\
\hline $\begin{array}{l}\text { cultura e patrimônio histórico e } \\
\text { artistico }\end{array}$ & 17 & $(5,7)$ & 5 & $(5,0)$ & 0,9 & 38 & $(6,0)$ & 4 & $(4,0)$ & 0,7 \\
\hline $\begin{array}{l}\text { desenvolvimento regional e local } \\
\text { em bases sustentáveis }\end{array}$ & 12 & $(4,0)$ & 6 & $(6,0)$ & 1,5 & 39 & $(6,2)$ & 6 & $(6,0)$ & 1,0 \\
\hline $\begin{array}{l}\text { formação de mão-de-obra e } \\
\text { geração de emprego e renda }\end{array}$ & 12 & $(4,0)$ & 6 & . $(6,0)$ & 1,5 & 16 & $(2,5)$ & 4 & $(4,0)$ & 1,6 \\
\hline formas de gestão e planejamento & 11 & $(3,7)$ & 3 & $(3,0)$ & 0,8 & 38 & $(6,0)$ & 10 & $(10,0)$ & 1,7 \\
\hline demais áreas & 113 & $(38,0)$ & 49 & $(49,0)$ & 1,3 & 269 & $(42,8)$ & 49 & $(49,0)$ & 1,1 \\
\hline
\end{tabular}

11) Áreas de ação governamental segundo nomenclatura adotada em 1997. Para 1996, os números foram calculados levando em consideração as modificações introduzidas.

Consideradas as sete áreas de ação com maior número de iniciativas inscritas em 1997, constata-se que apenas uma (formação de mão-de-obra e geração de emprego e renda) não estava entre as sete com maior número de iniciativas também no Ciclo de Premiação de 1996. A primeira, a segunda e a terceira áreas com mais projetos, programas ou atividades repetem-se nestas posições nos dois anos.

Algumas observações podem ser feitas quando analisamos separadamente os semifinalistas. Em 1997, os destaques mais positivos são para as iniciativas nas áreas "desenvolvimento regional e local em bases sustentáveis" e "formação de mão-de-obra e geração de emprego e renda", que tiveram metade dos inscritos classificados entre os 100 semifinalistas. A área "saúde" também apresentou "melhoria de desempenho" na comparação com 1996. Por outro lado, embora com presença expressiva entre as inscrições, as iniciativas nas áreas de "educação" e "criança e adolescente" acabaram classificando proporcionalmente poucos projetos, programas ou atividades entre os semifinalistas. 
Finalmente, é importante registrar a presença pouco expressiva - quase ausência de áreas de grande relevância no cenário da gestão pública brasileira, como o Legislativo, o Judiciário e a Segurança Pública.

Nestes breves comentários, feitos a título de introdução ao Banco de Dados de 1997, procurou-se apresentar um rápido painel acerca de alguns indicadores básicos sobre os projetos, programas e atividades inscritos no Ciclo de Premiação 1997 do Programa GESTÃO PÚBLICA E CIDADANIA; comparando-os, quando possível, com os dados relativos ao Ciclo de 1996. Uma análise mais aprofundada, que apontasse tendências de inovação, exigiria um olhar mais detalhado e qualitativo sobre as iniciativas inscritas. Não foi esta a intenção destas reflexões, que procuraram apenas fornecer aos interessados um quadro de algumas características agregadas das iniciativas inscritas em 1997, procurando ilustrar a vitalidade do nível subnacional de governo em nosso país. 